\title{
Application of Vehicle Restraint Systems (VRSs) in the State of Qatar: A Case Study from Northern Roads
}

\author{
Deepti Muley \\ deepti@qu.edu.qa \\ Qatar Transportation and Traffic Safety Center, Qatar University, Doha, Qatar \\ Shahram Tahmasseby \\ stahmasseby@qu.edu.qa \\ Qatar Transportation and Traffic Safety Center, Qatar University, Doha, Qatar \\ Bernd Wolfgang Wink \\ bw.wink@volkmann-rossbach.de \\ VOLKMANN \& ROSSBACH, Montabaur, Germany \\ Faris Tarlochan \\ faris.tarlochan@qu.edu.qa \\ Qatar Transportation and Traffic Safety Center, Qatar University, Doha, Qatar
}

\begin{abstract}
Recent developments within Infrastructural Road Safety and especially in the Sector of Vehicle Restraint Systems (VRS) have enabled Transport Authorities to significantly reduce road fatalities and severe injuries. Predominantly, two authorities have established leading guidelines for VRS installation and maintenance, - the European Union (EU) and the United States. The guidelines for the State of Qatar are based on these two sources. This technical paper briefly reviews the aforementioned guidelines, highlights the additional items in the EU guidelines, and explains the evolution of the State of Qatar guidelines accordingly. Moreover, this paper explains the application of VRS guidelines to the road network of the State of Qatar by presenting evidences from a recent site visit to the highways/expressways in the Northern Part of the Qatari Road Network. The outcomes of the site visit mainly highlight the typical steel VRS applied alongside the road (lateral as well as in central reserve, median), crash cushions, and various terminal systems. The paper is aiming to support designers, planners, auditors, contractors and installers to improve road safety from the VRS point of view.
\end{abstract}

Keywords: Road safety; Vehicle restraint systems (VRS); EN 1317; MASH; NCHRP 350

\section{INTRODUCTION}

Traffic accidents and consequent injuries and fatalities are a big and main concern of transport authorities all over the world. To reduce the number of serious injuries and fatalities due to traffic accidents, National Road Safety Strategy (NRSS) of State of Qatar has proposed increased installation of road safety barriers according to the state of the art, and designing of forgiving roads (NRSS, 2013). Furthermore, NRSS drew special attention to the treatment of medians, unprotected obstacles along the roadside, accesses and parking at intersections, and pedestrians exposed to high-speed traffic. The Public Works Authority (PWA), ASHGHAL, consequently decided to implement more advanced Vehicle Restraint Systems (VRSs) on newly designed roads in State of Qatar 
(Gulf times, 2016). Generally, VRSs are installed to (1) reduce the impact of collision through deformation to absorb the kinetic energy of the vehicle in a controlled way (tolerable deceleration values of the body), and (2) avoid sudden stopping of the vehicle and redirecting it back to the carriageway (Nyamakope, 2017). This paper presents an overview of guidelines for selection/installation of VRSs for the State of Qatar and explains the application of VRSs on Qatari roads using a case study.

\section{GUIDELINES FOR INSTALLATION OF VRS}

\subsection{Qatar standards}

ASHGHAL, the Public Works Authority in the State of Qatar has provided guidelines for the selection and implementation of VRSs for roads in the State of Qatar (PWA, 2015). Generally, authority approves three types of longitudinal barriers, i.e. rigid, semi-rigid, and flexible. The components of VRS include typical VRS for longitudinal protection as well as end terminals, crash cushions, transitions, and gates. It is mandatory to have barriers in accordance with EN1317 (European guidelines), NCHRP 350 and / or MASH (American guidelines) and then get approval from ASHGHAL. Primarily, the VRS should be crash tested in accordance with EN1317. Meanwhile, the VRSs passing the test as per MASH or NCHRP 350 will also be considered. Additionally, the in-service performance as well as availability of spare parts are also evaluated before approving a VRS. The safety performance of the VRS is firstly a result of structural adequacy (containment level), occupant risk (impact severity) and deformation of the system (working width), (see EN 1317 and MASH for details).

\subsection{European Union (EU) guidelines}

The European mandatory Standard EN1317 captures different components such as typical longitudinal safety barriers, terminals, transitions, removable barrier sections, and crash cushions along with pedestrian parapets (ECS, 2010). The test criteria specified in the standards are based on the "average or most frequent case". Furthermore, the EU Standard is focused on the collision of a human body [please refer to Acceleration Severity Index (ASI) for details]. The installation guidelines also mention mandatory requirements for maintenance of VRSs, which are not available in the American standards. Overall, the EU guidelines focus on deformable VRSs rather than rigid VRSs.

\subsection{American guidelines}

The recent American guidelines (MASH) evolved from an older report, called NCHRP 350, which was developed by Transportation Research Board (TRB), recommended testing the roadside features for severe vehicle impact conditions (Ross et al., 1993). Subsequently, MASH guidelines were developed presuming "worst practical conditions". The parameters such as test vehicle, impact speed and angle combination, test matrix, and point of impact were specified for most critical or worst conditions (MASH, 2009). Overall, the American guidelines are focusing on rigid VRSs rather than deformable VRSs.

\subsection{Potentials for the improvement of the PWA guideline}

The manuals recommended by ASHGHAL, PWA adopt the EU and American 
standards directly without stating any modifications according to local conditions of roads in the country. For instance, the requirements for cross slope varies for various European Union countries but the Qatari guideline does not specify any limits in this regard. Moreover, in the State of Qatar around one-third of total road fatalities are pedestrian fatalities (NRSS, 2013), but no specific requirements for VRS for these cases are set.

Another issue is that the vehicle structure on the roads is different from other developed countries because in the State of Qatar significant number of vehicles are Sport Utility Vehicles (SUVs) or four wheel drive. This implies that the test vehicle should be adjusted according to the local conditions. A study shows supporting evidence by suggesting modifications in VRSs based on the weights of vehicles in the system (Hernández et al., 2018). This fact should become reason for taking more care of the overall height of the VRSs to be installed. This implies that the local / Qatari conditions should be considered carefully when selecting the design and especially the installation height of the VRS to be applied in median and longitudinally.

\section{CASE STUDY}

The Qatar University team members with the Senior Manager of Volkmann \& Rossbach Gmbh \& Co. conducted a site visit on $22^{\text {nd }}$ October 2019 to a road network in the Northern Part of the State of Qatar. The route itinerary of the survey mainly constitute sections from Al Khor Coastal Road, Al Khor Link Road, , Al Huwailah Link and Al Shamal Road (Figure 1). Overall, $150 \mathrm{~km}$ of road network was surveyed. Table (1) summarises VRSs type (median and longitudinal sections) for the aforementioned corridors. For instance, on Al Khor Coastal Road, the median barrier is rigid (made by concrete). However, longitudinal sections' VRSs are predominantly made of steel.

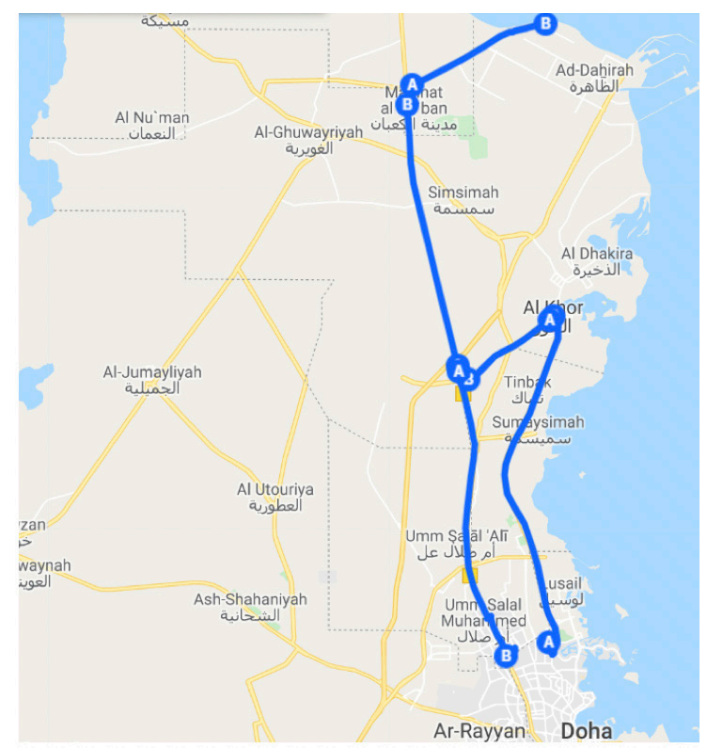

Figure 1: Route traversed for VRS site visit on Oct 22 $2^{\text {nd }}, 2019$. 
Table 1 Overview of VRSs installed on Northern roads in State of Qatar.

\begin{tabular}{|c|c|c|c|}
\hline $\begin{array}{c}\text { Name of road } \\
\text { section }\end{array}$ & $\begin{array}{c}\text { Length } \\
(\mathbf{k m})\end{array}$ & Medians & Type of VRS installed on \\
\cline { 3 - 4 } Al Khor Coastal Road & 36 & Concrete barriers H2 Level & $\begin{array}{c}\text { Concrete barriers as well as steel } \\
\text { barriers H2/H1 level }\end{array}$ \\
\hline Al Khor Link Road & 12 & Steel barriers H2 level & $\begin{array}{c}\text { Steel barriers H1 level } \\
\text { Mobile steel barriers H2 level, for } \\
\text { temporary applications }\end{array}$ \\
\hline Al Huwailah Link & 24 & Steel barriers H2 level & Steel barriers H1 level \\
\hline Al Shamal Road & 75 & Steel barriers H1 level & Steel barriers H1/H2/H4 levels \\
\hline
\end{tabular}

Note: Various types of crash cushions were observed on the roads. The poles for the bridges are protected by rigid concrete barriers as well as by steel barriers. Gates opening of the VRSs are steel barriers.

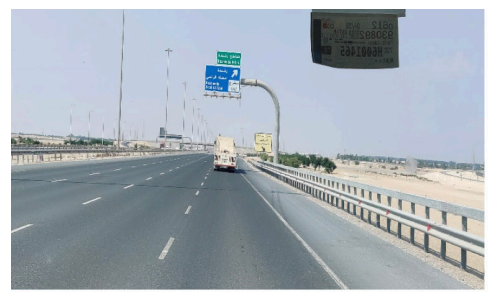

(a) H4 level steel barrier

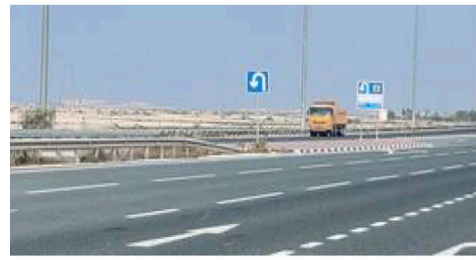

(c) End treatment (terminal)

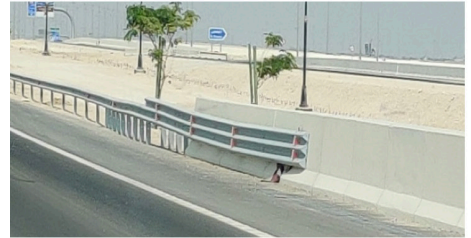

(e) Transitions

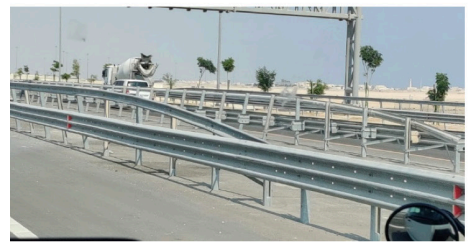

(g) Special treatments, steel barriers

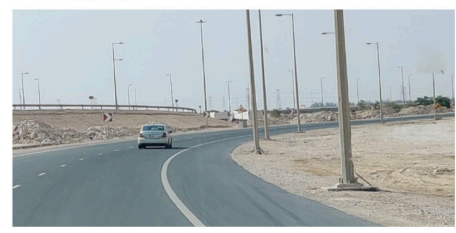

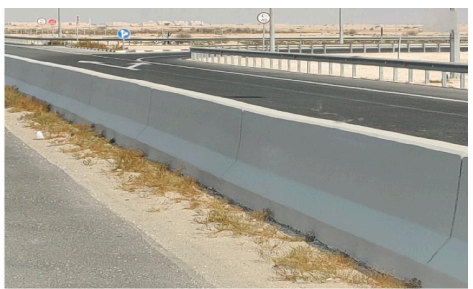

(b) Concrete barrier (rigid)

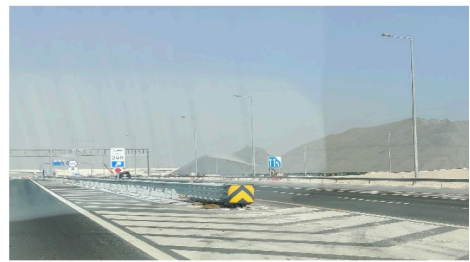

(d) Crash cushions

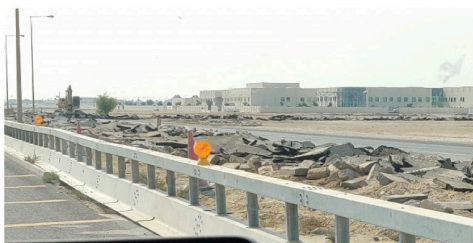

(f) H2 level mobile barriers

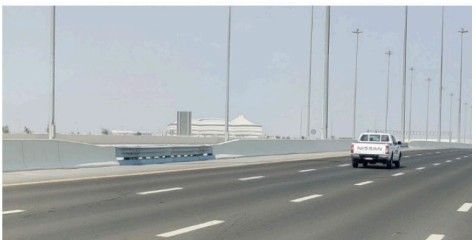

(h) Gate

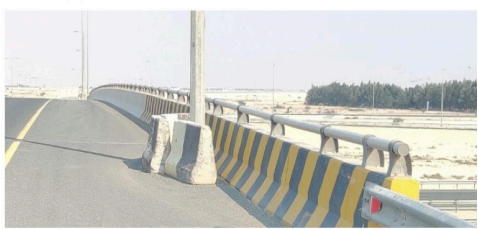

Figure 2: Various treatments used along Northern Qatari Roads. 


\subsection{Survey Findings}

- Most of the surveyed sections have advanced, state of the art VRS systems installed to significantly improve the road safety level on these sections of the Qatari Road network (Figure 2(a), (c), (d), (e), (f), (g), and (h)).

- The working width provided along the median of the surveyed roads is in most of the sections complying with the EU - (preferred) standards.

- At some sections, a combination of steel and concrete barriers is observed (Figure $2(\mathrm{e})$ ).

- Some sections were installed with a mobile type of barriers, which were tested for $\mathrm{H} 2$ level crash worthiness. These barriers possess highest safety features in spite of being mobile and fixed at the beginning and end-section, only (Figure 2(f)).

- In sections with gantries, light - posts, weigh - stations and pipe / gas -lines below the road, steel VRSs with the highest performance level on global scale (H4b according to EN 1317) have been installed (Figure 2(a) and(g)).

- The bridges pillars are protected by rigid concrete barriers as well as steel barriers.

\subsection{Observed Shortcomings}

- It was observed on some of the road sections that dangerous hazards like gantries , light -posts etc. are too close to the VRS , mostly because of design - reasons like foundations already made and not changeable anymore, excavation issues, etc., resulting in insufficient space for the efficient working width of the VRS.

- The barriers damaged due to crashes have to be changed or repaired as quickly as possible to ensure that the functionality of VRS is maintained. An observation was made near Ras Laffan site that a heavy accident took place long time ago, but damaged VRS is still not repaired.

- Unprotected concrete blocks were observed at some sections, especially on bridges, which should be replaced with a safer system urgently. Forefront crash cushions installation can enhance the safety of concrete barriers over bridges (see figure 2 (j) for more details).

- Some sections, predominantly ramps were having no VRS or partial VRS installed, please see Figure 2(i) for details.

\section{LESSONS LEARNED}

The site visit to the roads in northern parts of State of Qatar suggested that the major part of these roads are equipped with very advanced VRSs of highest level on a global scale. The consideration of the following criteria would enhance the road safety level further in the State of Qatar:

- The European and American standards should be applied in consideration of the special, local and fleet related requirements in the State of Qatar.

- The frequency of the maintenance of VRSs should be specified and authorities need to adhere to it consequently.

- The repair or replacement of the damaged VRS units should be undertaken as soon as possible.

- It is recommended that the design and planning of the installation of VRSs should be undertaken at the design stage of the road and not at the audit stage. 


\section{CONCLUSION}

Authorities in the State of Qatar set guidelines for the installation of VRSs predominantly based on the European Union (EN1317) and American (MASH) standards widely practiced in the world. Consequently, the newly developed roads benefit from advanced / latest VRSs, which are designed and installed to enhance road safety and protect the drivers and vehicles from suffering severe damage. Nevertheless, at some sections missing or hazardous segments are observed. These should be corrected to avoid any chance of crucial vehicle crashes. Furthermore, frequent maintenance of these sections should be scheduled and adhered to. It is also recommended that a specific VRS guideline is drafted, based on the country road traffic conditions, posted versus observed speed as well as the vehicle composition in which a significant portion is SUV vehicles.

\section{REFERENCES}

ECS (2010). Road restraint systems part 1 to 3. European Committee for Standardization, EU.

Gulf Times (2016). https://www.gulf-times.com/story/517778/Safety-barriers-bring-in-drasticreduction-in-traffic-death-rates, accessed on 26 November 2019.

Hernández, Z. A., Álvarez, F., Alonso, M. \& Sañudo, L. (2018). Analysis of the test criteria for vehicle containment systems in the standard EN 1317 regarding the number of vehicles in use. Transportation Research Procedia, 33, 315-322.

MASH (2009). Manual for assessing safety hardware, American Association of State Highway and Transportation Officials), United States of America. ISBN 978-1-56051-416-9.

NRSS (2013). National road safety strategy 2013 - 2022. National Traffic Safety Committee, State of Qatar.

Nyamakope (2017). Vehicle restraint systems and their function: restraining and containing traffic, accessed at http://www.engineersjournal.ie/2017/06/20/vehicle-restraint-systemsfunction/ on 26 November 2019.

PWA (2015). Road safety barrier systems - Accepted for use on roads managed by the Ashghal Public Works Authority (PWA), Ashghal, State of Qatar.

Ross, H. E., Sicking, D. L. \& Zimmer, R. A. (1993) Report 350 Recommended procedures for the safety performance evaluation of highway features, Transportation Research Board, National Academy Press, Washington, D.C.

Cite this article as: Muley D., Tahmasseby S., Wink B. W., Tarlochan F., "Application of Vehicle Restraint Systems (VRSs) in the State of Qatar: A Case Study from Northern Roads", International Conference on Civil Infrastructure and Construction (CIC 2020), Doha, Qatar, 2-5 February 2020, DOI: https://doi.org/10.29117/cic.2020.0058 